\title{
Video streaming over Ad hoc on-demand distance vector routing protocol
}

\author{
Othman O. Khalifa ${ }^{1}$, Diaa Eldin Mustafa Ahmed ${ }^{2}$, Aisha Hassan Abdalla Hashim ${ }^{3}$, Mudathir Yagoub ${ }^{4}$ \\ ${ }^{1,3}$ Department of Electrical and Computer Engineering, International Islamic Unicersity Malaysia, Malaysia \\ ${ }^{2,4}$ Department of Information Technology, University of Sciences and Technology, Sudan
}

\section{Article Info \\ Article history: \\ Received Feb 27, 2019 \\ Revised May 2, 2019 \\ Accepted May 16, 2019}

\section{Keywords:}

AODV

MANETs

Performance evaluation

Video streaming

Wireless network

\begin{abstract}
Video streaming is content sent in compressed form over the netwoks and viwed the users progressively. The transmission of video with the end goal that it can be prepared as consistent and nonstop stream. The point is that to give client support to client at anyplace and at whatever time. Mobile Ad hoc Networks (MANETs) are considered an attractive nertwork for information transmission in many applications where the customer programme can begin showing the information before the whole record has been transmitted. Ad hoc On-demand Distance Vector (AODV) protocol is considered as one of the most important routing protocols in MANET. However, routing protocols assume a crucial part in transmission of information over the network. This paper investigates the performance of AODV Routing Protocol under video traffic over PHY IEEE 802.11g. The protocol model was developed in OPNET. Different outcomes from simulation based models are analyzed and appropriate reasons are also discussed. A different scenarios of video streaming were used. The metric in terms of throughput, end to end delay, packet delivery ratio and routing overhead were measured. A comparision with GRP and GRP are also reported.
\end{abstract}

Copyright (c) 2019 Institute of Advanced Engineering and Science. All rights reserved.

\section{Corresponding Author:}

Othman O. Khalifa,

Department of Electrical and Computer Engineering,

International Islamic University Malaysia,

Jalan Gombak, 53100 Kuala Lumpur, Malaysia.

Email: khalifa@iium.edu.my

\section{INTRODUCTION}

In early days for watching video from a specific site first we need to download it and after that play. Currently, video can be palyed when it begins downloading. However, video streaming requires adequate data transfer capacity to play, particularly at higher quality. At that point, finding fitting routing protocol for maintaining video movement is a fundamental issue. The aim to enhanced Video Streaming to satisfy the users demand. Mobile ad hoc networks (MANETs) is a peer-to-peer communication technique arises when a group of mobile nodes (MNs) can performed a communications through multi-hop routing using the multihop wireless link without centralized administration. It becomes popular and gain a great deal of importance from both of the researchers and industry in information transmission. MANET is a group of wireless mobile nodes (Mobile phone, laptop, PDA, MP3 player and etc...) which can act as a transmitter, router or receiver. MANET [1-5]. It is homogeneous when the mobile nodes (MNs) are similar structure, platforms and equal capabilities and responsibilities to perform, and heterogeneous when otherwise. In MANETs nodes that are free in moving in and out in the network, any new node can join the network at any time anywhere, likewise any node can leave the network. MANETs have promising features such as topological flexibility, fast deployment, mobility, robustness, fault resilience, self healing and independence of fixed infrastructure spark off. However, routing protocols establishes the governing rules and spiffy the set of parameters that indicate how the data information are exchanged between different nodes in networks [2]. Recently, researchers 
proposed many routing protocols algorithms to overcome the challenges of MANETs and to solve the facing problems such as failure due to node mobility, limited power on mobile nodes, topology changes, limited bandwidth, link, power consumption, etc. This paper investigates the performance of Ad hoc On-Demand Distance Vector (AODV) Routing Protocol under Video Streaming [6-8].

\section{VIDEO STREAMING}

Streaming is a technique for transferring data in such a way that it can be processed at a steady and continuous stream. Video streaming over computer networks is considered to become the most interesting application in the near future [9], [10]. There are three types of delivery methods of streaming media; Streaming Stored Audio and Video, Streaming Live Audio and Video and Real-Time Interactive Audio and Video. The video and audio streams compressed/stored then encapsulated during network layers and transmitted by transport protocols via the internet to the client side. While they are handled on the other side in an opposite way to be viewed by the user. Figure 1 shows the overall architecture for video streaming.

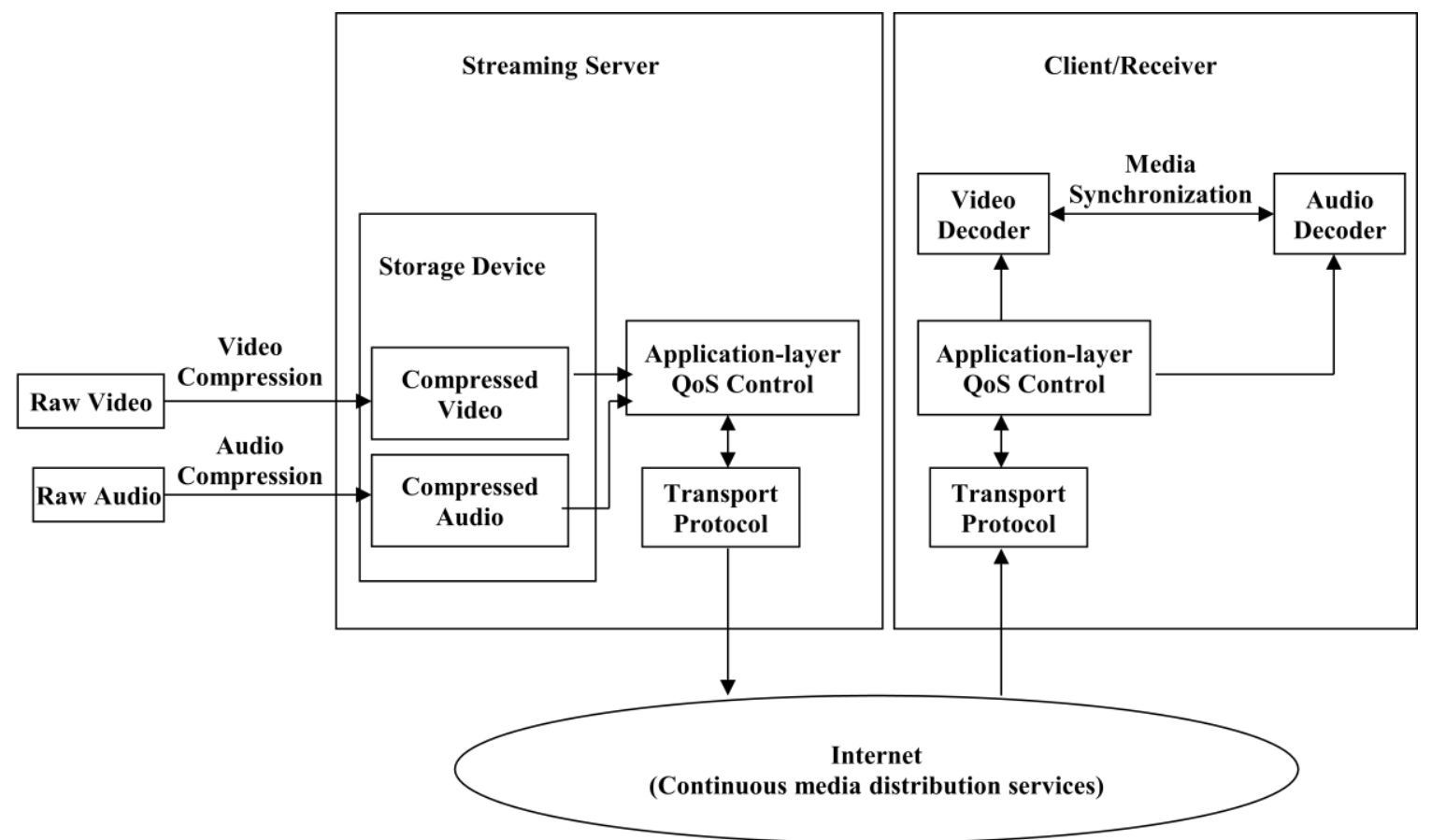

Figure 1. Architecture for video streaming

This kind of application needs large bandwidth, efficient routing protocols, and content delivery methods to provide smooth video playback to the receivers. Video streaming systems are classified into two categories including:

a. Live video Streaming

In live video streaming, synchronized streams are played back in all nodes, and all users watch the same video frames simultaneously.

b. Video on Demand

(VoD) streaming, users watch different video frames of the same video stream at a given instant of time. In other words, the playbacks of the same video streams on different clients are not synchronized for a VoD streaming.Real-time multimedia data applications, such as video streaming and video telephony, are regarded as "killer applications" in the emerging wireless networks. Video applications usually involve a large volume of data transmitted in a time sensitive fashion [11]. However, the underlying wireless networks only provide time-varying and limited bandwidth, high data error rate, packet delay and jitter. Extensive research has been done on either video data coding algorithms or wireless network protocols. But the traditional layered network model limits the video transmission over wireless networks because it tries to separate information and functions between different layers [12]. To enable more efficient real-time data transmission over dynamic wireless environments, the applications and underlying wireless networks should 
cooperate in order to share information and optimize the transmission process dynamically. In this parts reviews the state-of-the-art research efforts on video coding, error control, and rate control algorithms. New cross-layer algorithms are presented which coordinate the algorithms at different layers in order to get better performance than using them separately. The cross-layer rate control algorithm matches the application's future bandwidth requirement to the available bandwidth in the network so that an optimum data transmission rate can be selected. In the cross-layer error control algorithm, lower layers are responsible for error detection and fast retransmission, while application layer conducts an adaptive error correction algorithm with the help of lower layers [13].

Multimedia services and applications became the driving force in the development and widespread deployment of wireless broadband access technologies and high speed local area networks. Mobile phone service providers are now offering a wide range of multimedia applications over high speed wireless data networks. People can watch live TV, stream on-demand video clips and place video telephony calls using multimedia capable mobile devices. The variety and quality of these applications are increasing every day. Mobile devices will soon support capturing and displaying high definition video. Similar evolution is also occurring in the local area domain. The video receiver or storage devices were conventionally connected to display devices using cables. By using wireless local area networking (WLAN) technologies, convenient and cable-free connectivity can be achieved. Media over wireless home networks prevents the cable mess and provides mobility to portable TVs [14].

However, there still exits challenges for improving the quality-of-service (QoS) of multimedia applications. Conventional service architectures, network structures and protocols lack to provide a robust distribution medium since most of them are not designed considering the high data rate and real-time transmission requirements of digital video [15].

\section{VIDEO TRANSMISSION TECHNIQUES OVER MANETS}

Due to the demand of users, video streaming must be made possible as the satisfaction of receivers in real-time in Mobile Ad hoc Networks. Changes in topology, Mobility of nodes, life of battery, security threats and protocols affect the performance of MANET. To provide efficient QoS in MANET, there is a solid need to investigate and identify the effect of number of mobile nodes, the network size and mobility speed on QoS [9]. The Video transmission techniques over MANETs can be classified into three main techniques; Coding techniques, Layering techniques and Routing techniques as shown in Figure 2. However, video streaming in real time requires special techniques that can overcome the losses of packets in the unreliable networks.

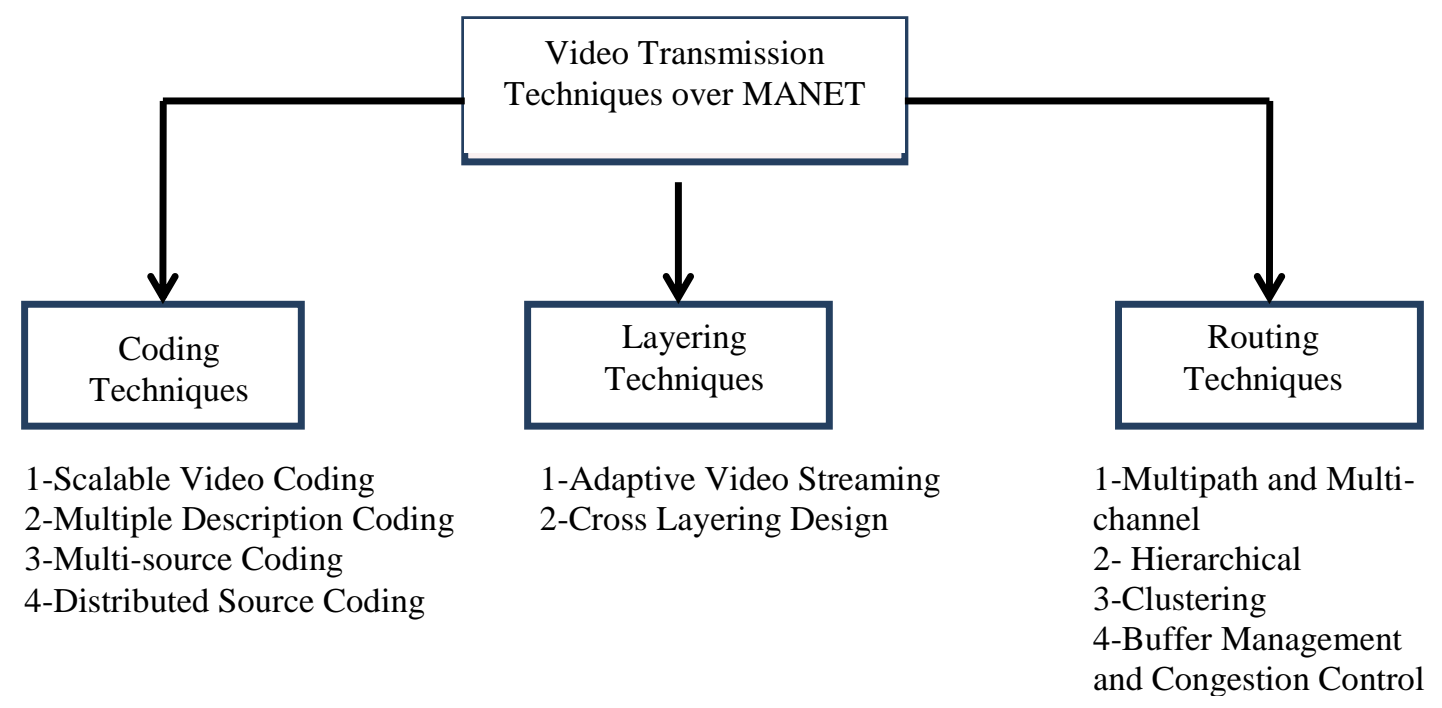

Figure 2. Video transmission techniques over MANETs

\section{AD HOC ON-DEMAND DISTANCE VECTOR (AODV)}

AODV is a reactive routing protocol designed for MANETs networks. It is proposed by Charles Perkins and Elizabeth Royer in 1999 [9]. AODV is an on-demand routing protocol developed with the 
combination on the DSDV and DSR algorithm, it establishes routes between nodes only as needed by source nodes. AODV need not a routing table, it maintains their routes as long as they are needed by the sources. According to their structure, AODV forms trees edges which support it to connect multicast group of mobile nodes $(\mathrm{MN})$. These trees are composed of the group of $(\mathrm{MN})$ and the intermediate nodes required to connecting the (MN) as a group of members. AODV protocol has important advantages, a) uses sequence numbers to ensure the freshness of links; b) guarantee loop-free, self-starting, and c) supported scalability to large numbers of mobile nodes. AODV uses flooding in order to find the paths requested by a sender node, for this purpose AODV uses route request message RREQ flooded through the entire network, where the RREQ have the current sequence number for the sink node of which the sender node is aware and from then any received node a RREQ should acknowledge to it using a RREP message only if it has a route to the required sink node. In summary, AODV defines three types of control messages for route maintenance as shown in Figure 3.

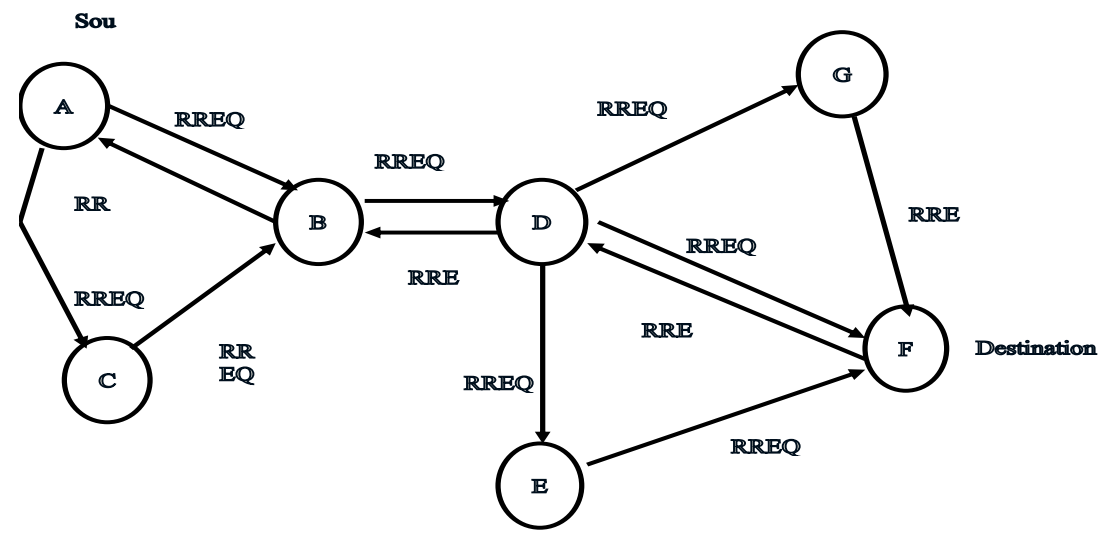

Figure 3. Possible path for route replies if node $\mathrm{A}$ wishes to find a route to $\mathrm{F}$

\section{RELATED WORKS}

Many works have been done in the area of routing protocols in MANETs. Different protocols had been evaluated using a different kind of simulators such as NS-2, OPNET, OMnet++ and other simulation tools. The performance evaluation performed to investigate the feasibility, reliability and the quality of service (QoS). The following paragraph showed the state of art and most important studies done recently: Hazzaa et al.(2017) [16] evaluated the performance of AODV for multimedia traffics (FTP, Voice, Video Conference) in terms of delay, throughput, network load, retransmission attempts as QoS parameters for MANET network, and they used route discovery time, routing traffic received, routing traffic sent as QoS parameters for the AODV protocol. Their simulation works implemented in the environment of OPNET modular and show that there are significant differences between the three types of multimedia traffics .They conclude that the impact of traffic type on MANET depend on the QoS requirements for each type of traffics. Kushwaha et al. (2016) [17] compared between three MNETs routing protocols DSDV, DSR and AODV for CBR traffic using OPNET simulator. They carried out from the simulation that in all three protocols, DSDV is showing better performance than AODV and DSR, however, in exponential traffic AODV has better performance than DSDV. In addition, after analyzing all three protocols it can be observed that there are optimal values of packet size and offered load for which value of throughput and PDR values are optimal, after that their values are decreased or become constant. Ramakant et al.(2015) in their research paper [18] performed a simulation of three MANETs routing protocols AODV, DSR and DSDV on the basis of three performance parameters packet delivery ratio (PDR),end-to-end delay and throughput via using NS-2 simulator. Their observations from the simulation works show that DSR is better for small number of nodes but for large number of nodes, DSDV is superior. Also their study show that AODV is better throughput compared to other protocols DSR and DSDV. The main disadvantages of their works they don't mentioned the simulation duration time and data rate among coverage WLAN protocol IEEE802.11. However in that study the authors can use any hybrid routing protocol such as ZRP or DDR to comparing it with reactive and proactive routing protocols used in that study.

Alqaysi et al. (2015) in their paper [20] analyzed and compared two MAN ETs routing protocols AODV and OLSR with transmitting video streaming application in terms of end-to-end average delay, load, retransmission attempts, and throughput using OPNET. They found that the proactive protocol OLSR is 
verified to be very efficient and effective routing protocol for MANETs for real-time data transmission such as video streaming or video conferencing. The main disadvantages of their simulation work are the fixed number of mobile nodes (60) which can't represent the real live scenario in this case. In [21] and [22], they analyzed the performance of multimedia traffic in MANETs with various mobile subscriber speed by using CBR and VOIP connection using Qualnet 6.1 simulator in terms of throughput, end to end delay, and total data received. They concluded that the overall performance of routing protocol for CBR and VOIP at 0 to 10 mbps is better than CBR and VOIP at 0 to $20 \mathrm{mbps}$. The disadvantage of their study is they don't show at what data rate in the PHY/IEEE 802.11/n protocol they simulate the multimedia traffics.

\section{PERFORMANCE EVALUATION PARAMETERS}

a. Average Packet-End-to-end delay(E2E)

End-to-end delay or sometimes called one-way delay (OWD) of a network is defined as how much time taken by the network to sent information data with a unique ID from source to destination (successful packet transmission). E2E delay $\left(\mathrm{D}_{\mathrm{E} 2 \mathrm{E}}\right.$ ) includes all possible delays in the network such as (route discovery latency, queuing delay at the interface queue, retransmission delay by the MAC, processing delay, propagation delay, MAC control overhead and intermediate nodes delay) as shown in Eq.(2). To calculate the average E2E delay $\left(\mathrm{AV}_{(\mathrm{E} 2 \mathrm{E})}\right)$ the possible delays were added for each information data packet sent successfully $\mathrm{i}$ and divided the accumulative sum by the number of received information data packets $(\mathrm{N})$ as in (3). A routing protocol with minimum delay represents the reliability of a network. In fact, E2E is important criteria for multimedia applications;

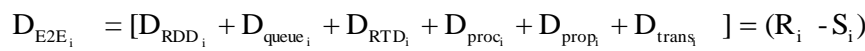

$$
\begin{aligned}
& \mathrm{AV}_{(\mathrm{E} 2 \mathrm{E})}=\frac{1}{\mathrm{~N}} \sum_{\mathrm{i}=1}^{\mathrm{n}}\left(\mathrm{R}_{\mathrm{i}}-\mathrm{S}_{\mathrm{i}}\right)
\end{aligned}
$$

where : $D_{R D D_{i}}=$ Route Discovery Delay

$D_{\text {queue }_{i}}=$ Queuing delay

$D_{R T D_{i}}=$ Retransmission delays at the MAC layer

$D_{\text {proc }_{i}}=$ Processing delay

$D_{\text {prop }_{i}}=$ Propagation delay

$D_{\text {trans }_{i}}=$ Transmission delay

$\mathrm{N}=$ The number of $\mathrm{d}=$ succrssfully received packets

$R_{i}=$ Is time at which a packet with unique id I is received

$S_{i}=$ Is time at which a packet with unique id is sent

b. Packets Delay Variation (jitter (sec))

Jitter is the variation in time between arrivals of packets. The difference in end-to-end one-way delay between selected packets in a flow with any lost packets being ignored. However, low jitter is especially important metric for real-time

c. Packet Delivery Ratio (PDR)

It is an important metric in networks, it is defined as the ratio between all the received information packets at the sink node and the number of data information packets sent by all the sources nodes. For multimedia application is desired high.

$$
\text { PDR }=\frac{(\text { Data informatio } n \text { Packets Received at sink node })}{(\text { Data Information Packets sent by source node })} * 100
$$

\section{d. WLAN-E2E-Delay (E2ED)}

It is determined the average time that packets require from the source to the application layer at the destination node. It is expressed in seconds.

e. Throughput (bits/sec)

In MANETs throughput is considered as an important parameter to measure the robustness of the network. 
Throughput $=\frac{(\text { No of Bytes Received } * 8)}{(\text { Simulatio } n \text { Time } * 1000)} \mathrm{kbps}$

\section{f. WLAN Load}

It is the total load (in bits/sec) send through wireless LAN layers by all higher layers in all WLAN nodes of the network.

g. Total packets dropped

This metric is important for video streaming applications because they are sensitive for packets dropped or loss which can affect quality of video.

\section{SIMULATION SETUP}

OPNET 17.5 modular is used for to analysis and test the performance of comparative routing protocol AODV. The parameters considered in this scenario are shown in Table 1.

Table 1. Simulations Parameters

\begin{tabular}{ll}
\hline $\begin{array}{l}\text { Parameter } \\
\text { WLAN Network simulation Parameters }\end{array}$ & Value \\
\hline Network Area(Size) $\left(\mathrm{m}^{2}\right)$ & SZ 500x500 \\
& MZ 1000x1000 \\
& LZ 1500x1500 \\
WD $(5,10,15,20,25,30,35)$ MD $(40,50,60,70)$ \\
Wireless Nodes & HD $(80,90,100)$ \\
Node Speed (m/s) & {$[0,10]$ and $[10,25]$} \\
MAC Layer Protocol & PHY IEEE 802.11g \\
Data Rate (Mbps) & 54 \\
Channel Settings & Auto Assigned \\
Buffer Size (bits) & $256000=32 \mathrm{~KB}$ \\
Transmit Power (Watt) & 0.005 \\
Packet Reception & -95 \\
Power Threshold(dBm) & \\
Link Delay Threshold (sec) & 0.1 \\
MANETs routing Protocols & AODV \\
Simulation Time(sec) & 800 \\
Addressing Mode & IPv4 \\
Simulator & OPNET 14.5 \\
\hline
\end{tabular}

To evaluate the Adhoc networks, mobility and traffic generation are two significant factors affecting protocol performance. The Mobility Model Parameters is shown in Table 2 where the uniformly and randomly chosen destinations (random waypoint model) is used. Here, a node chooses a random destination anywhere in the network field. The node moves towards that destination with a velocity chosen randomly from $[0$, Vmax $]$. After reaching the destination, the node stops for a duration defined by the "pause time" parameter. This procedure is repeated until the simulation ends. Table 3 shows the MANETs Traffic Generation Parameters. While Table 4 shows Video Traffic Parameters.

Table 2. Mobility model parameters

\begin{tabular}{ll}
\hline Parameter & Value \\
Mobility Model (Random Waypoint Parameters) & \\
\hline x_max (meters) & 500 \\
y_max (meters) & 500 \\
Speed (meters/seconds) & uniform_int $(0,10)$ for low mobility and, uniform $(10,25)$ for high mobility \\
Pause Time (seconds) & constant $(100)$ for low mobility and constant $(0)$ for high mobility \\
Start Time (seconds) & constant $(100)$ \\
Stop Time(seconds) & End of Simulation \\
\hline
\end{tabular}


Table 3. MANETs traffic generation parameters

\begin{tabular}{ll}
\hline Parameter & Value \\
\hline MANET Traffic Generation Parameters & \\
\hline Time in seconds & 100 \\
Inter-arrival Time Packet (sec) & Exponential -01 \\
Packet Size in bits & Exponential -1024 \\
Destination IP Address & Random \\
Stop Time in seconds & End of Simulation \\
\hline
\end{tabular}

Table 4. Video traffic parameters

\begin{tabular}{ll}
\hline Parameter & Value \\
\hline Application Parameters & \\
\hline Application & Video conferencing \\
Frame Size Information (bytes) & $128 X 240$ pixels \\
Type of Service & Best effort $(0)$ \\
Application Segment Size & 64.000 or 32.000 \\
Frame Size & 256 \\
Maximum available bandwidth $(\mathrm{MHz})$ & 10 \\
\hline
\end{tabular}

In this work, Ad hoc On-demand Distance Vector (AODV) routing protocol is considered. Table 5 shows AODV Protocol Parameters. AODV routing reactive an on demand routing protocols in the network. The AODV protocol wants to determine an only path foundation node to end nodes regarding packet massages data transfer in the network.

Table 5. AODV protocol parameter

\begin{tabular}{lc}
\multicolumn{1}{c}{ Parameter } & Value \\
\hline Active Route Timeout $(\mathrm{sec})$ & 3 \\
Hello Interval(sec) & uniform $(1,1.1)$ \\
Allowed Hello Loss $(\mathrm{sec})$ & 2 \\
Net Diameter & 35 \\
Node Traversal Time(sec) & 0.04 \\
Route Request Retries & 5 \\
Route Request Rate Limit (pkts/sec) & 10 \\
Route Error Rate Limit (pkts/sec) & 10 \\
Timeout Buffer(sec) & 2 \\
\hline
\end{tabular}

\section{RESULTS AND DISCUSSION}

The performance of the routing protocol AODV was evaluated using Video Conferencing with low mobility and small scale. In this scenario, the routing protocol under IEEE $802.11 \mathrm{~g}$ for video streaming traffic using node density $5,10,15,20,25,30,35$ with mobility speed in the interval $[0,10] \mathrm{m} / \mathrm{s}$ and network size $100 \times 100 \mathrm{~m} 2$ with the addition of other parameters described in the previous tables. We evaluated the performance in terms of the E2E delay in seconds, throughput (bits/sec), Packet Delivery Ratio, Routing Overhead. Figure 4 shows the calculated average E2E delay of each transmitted data packets during the simulation time as a function of node density. E2E delay includes all possible delays as we mentioned before in (1) and (2).

From Figures 4 till 8, observed that, there are sharp variations (increases or decreases) in some nodes with respect to packet metrics (delay, jitter, delivery ratio) or in node density or throughput or routing overhead. All these variations according to video content in terms of weight or lightness. The performance results are tabulated in Table 6. Where AODV protocol very good in Throughput and Acceptable in Packet E2E, C Packet Delay Variation (Jitter), WLAN-End-to-End Delay, Retransmission Attempts(packets, Network Load and Network Load. However, AODV protocol not good in Packet Delivery Ratio and Total Packets Dropped. 


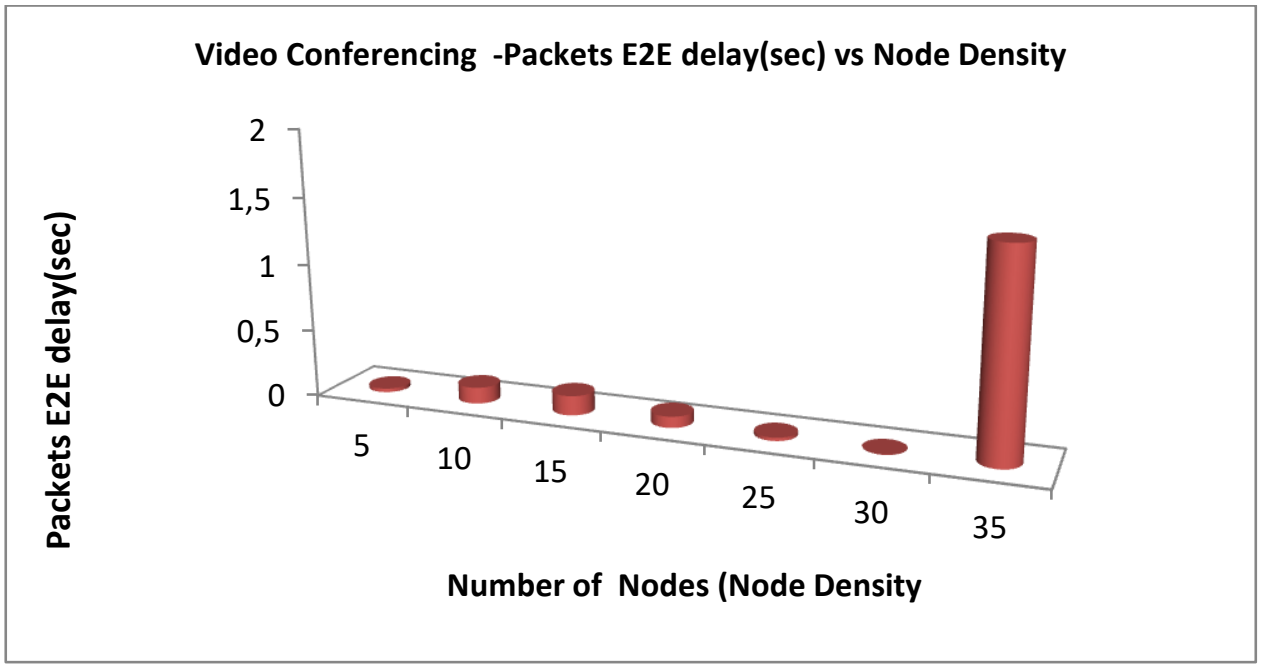

Figure 4. Packets E2E delay (sec) vs node density

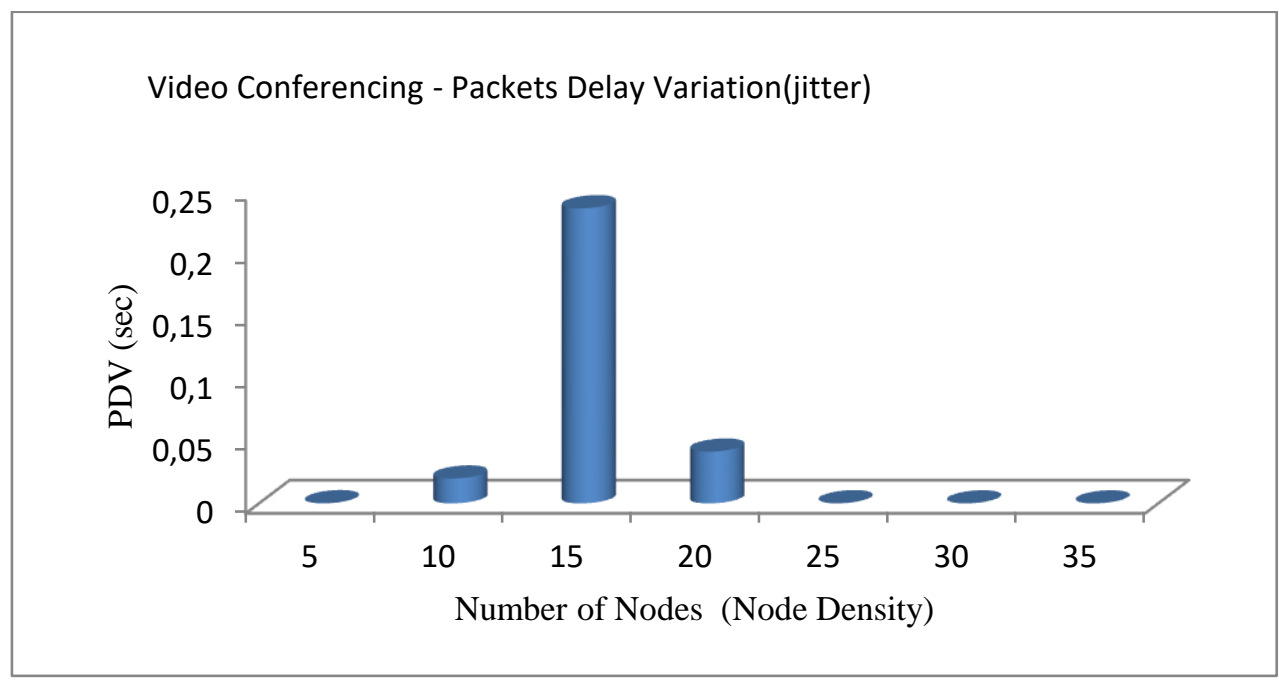

Figure 5. Packets delay variation (jitter)

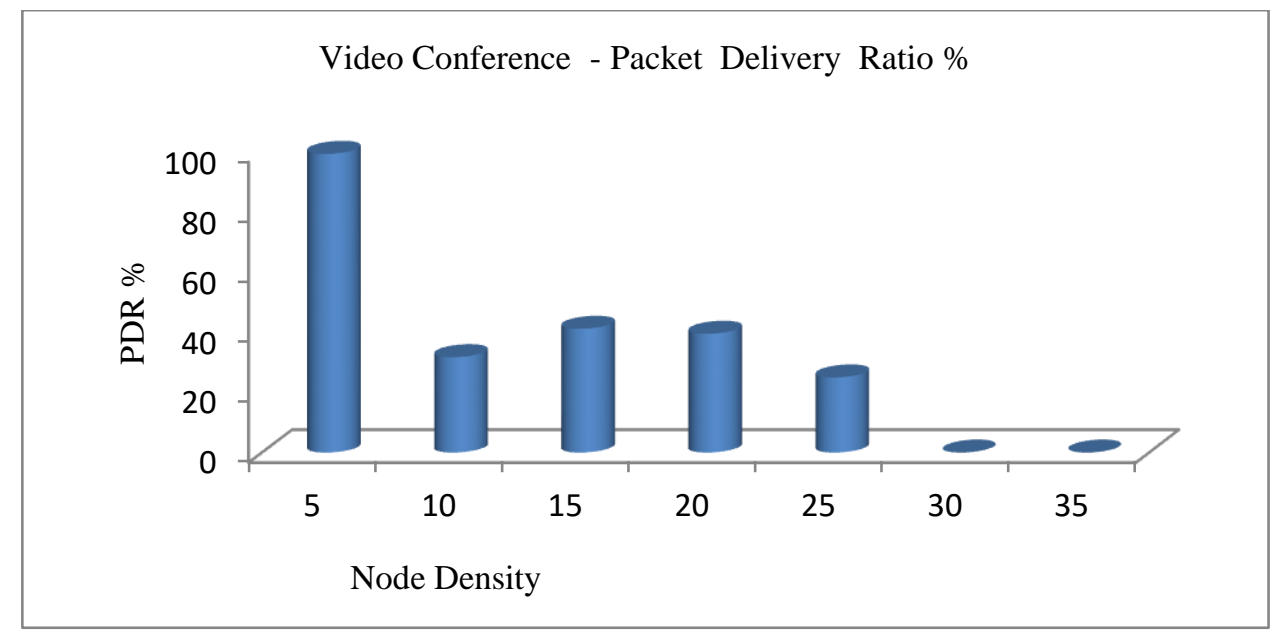

Figure 6. Packet delivery ratio \% 


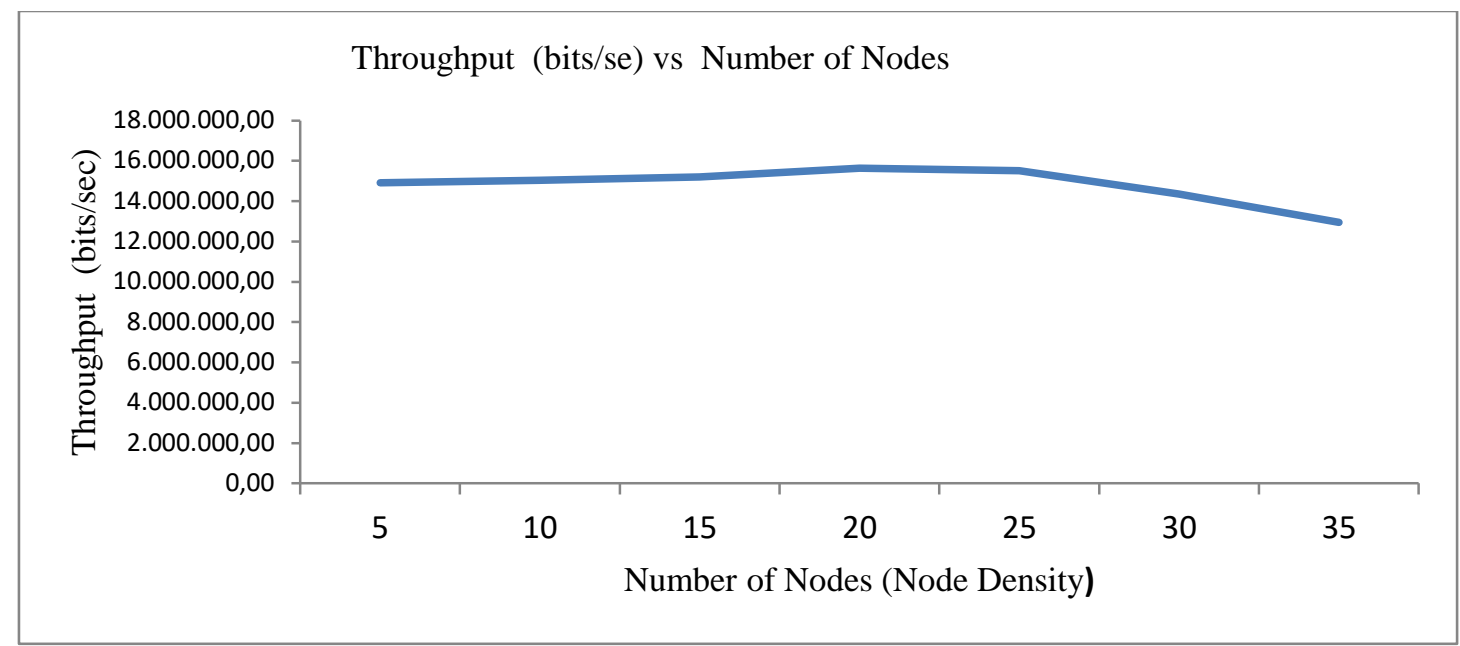

Figure 7. Throughput (bits/se) vs number of nodes

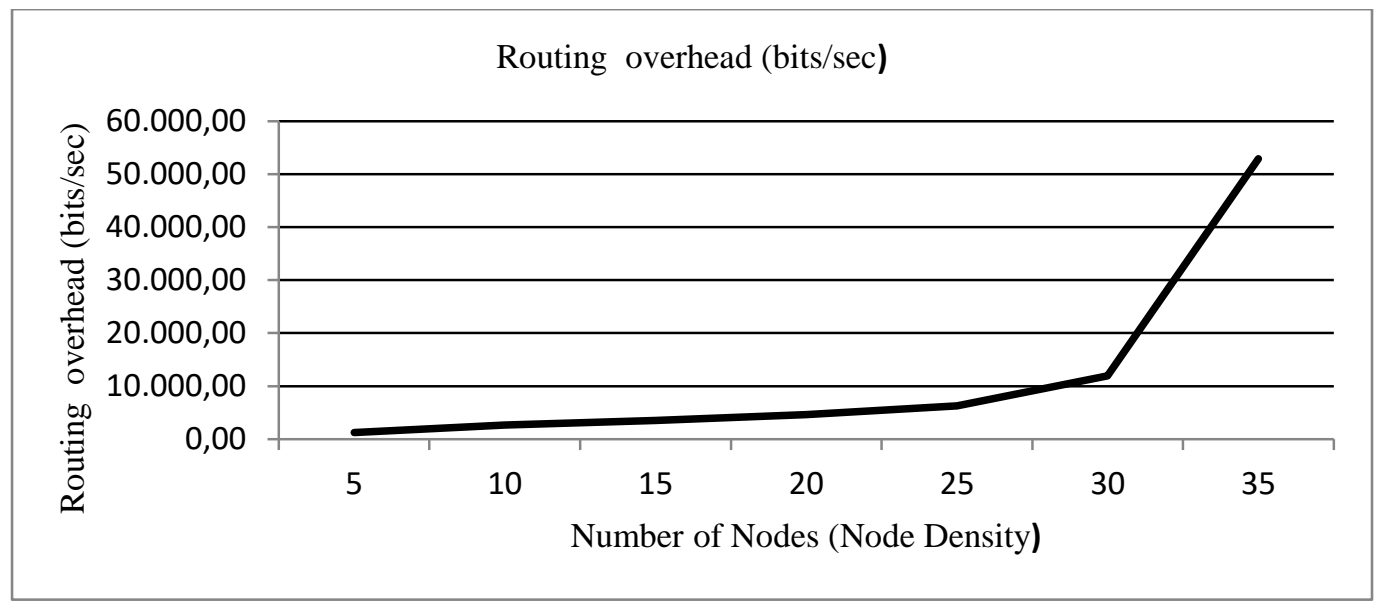

Figure 8. Routing overhead (bits/sec)

Table 6. A summary of AODV performance

\begin{tabular}{|c|c|}
\hline Protocol & AODV \\
\hline 1-V.C. Packet E2E delay (msec) & Low \\
\hline $\begin{array}{l}\text { 2-V.C Packet Delay Variation } \\
\text { (Jitter) }\end{array}$ & Low \\
\hline 3-Packet Delivery Ratio (PDR \%) & V. Low \\
\hline 4- WLAN-End-to-End Delay (sec) & Low \\
\hline 5- Throughput (bits/sec) & V. High \\
\hline 6-Retransmission Attempts(packets) & Less \\
\hline 7-Network Load (bits/sec) & Low \\
\hline 8-Total Packets Dropped (packets) & \\
\hline 9- Network Load (packets/sec) & Low \\
\hline
\end{tabular}

Comparing AODV with GRP and GRP during transmitting real-time video conferencing. Simulation shows that if the number of nodes starts to increase, jitter in AODV increases (97.42 sec with 60 mobile nodes), which is not acceptable compared with the desired value according to criteria parameters as shown in Figure 9. Therefore AODV is very poor and worst in terms of jitter because AODV is generally a demand-based routing protocol. Geographical protocols take advantage of nodes location information to compute routes and this will improve scalability and reduce the network traffic.GRP outperform AODV and 
OLSR in terms of jitter due to its accuracy of determining the position and compute the path between the source and destination and at the same time maintain the link breakage efficiently. The jitter value in case of GRP is out of range [169 ms at 50nodes 2sec at 80 nodes], but if we reconfigure it with suitable parameters we will enhance their performance in terms of jitter. AODV is not suitable for dense and highly dynamic networks.

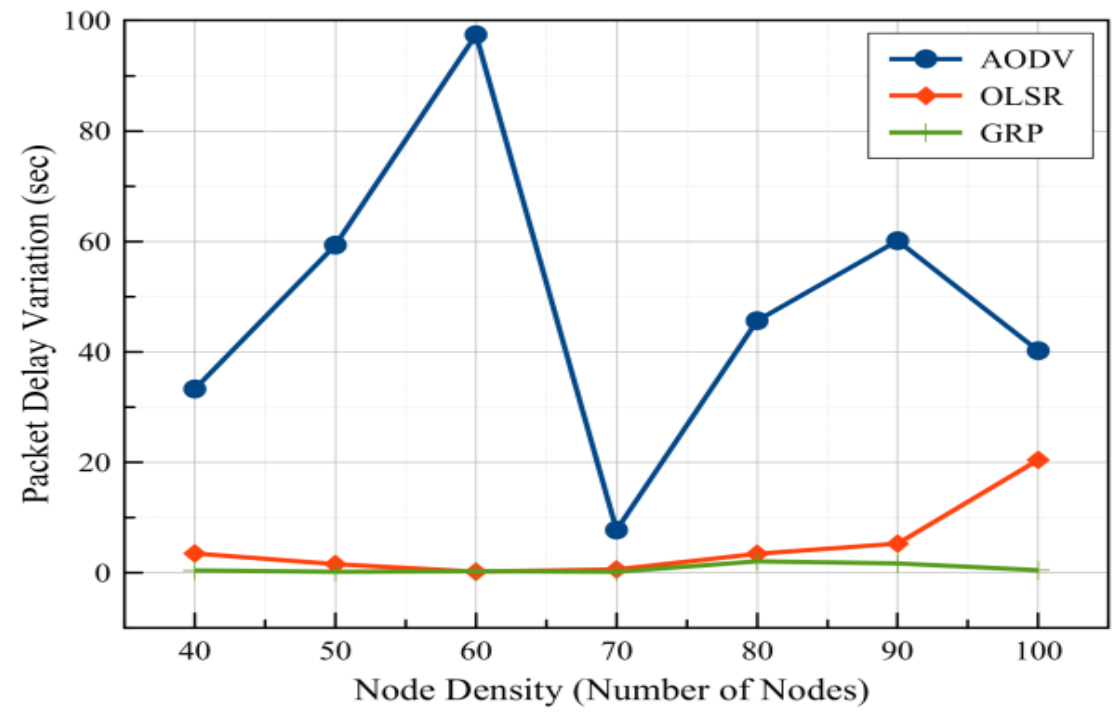

Figure 9. Jitter (sec) vs node density

In large network sizes, nodes frequently experience route breaking and elapse more time to find an efficient route. So packet loss and E2ED are increased. Figure 10 shows the data dropped (bits/sec), OLSR is the lowest data dropped compared with AODV and GRP. AODV is similar to OLER data dropped in the range [70 to 80] mobile nodes, but if the number of mobile nodes exceeds 80 nodes data dropped start to increases. GRP is the worst case in terms of data dropped.

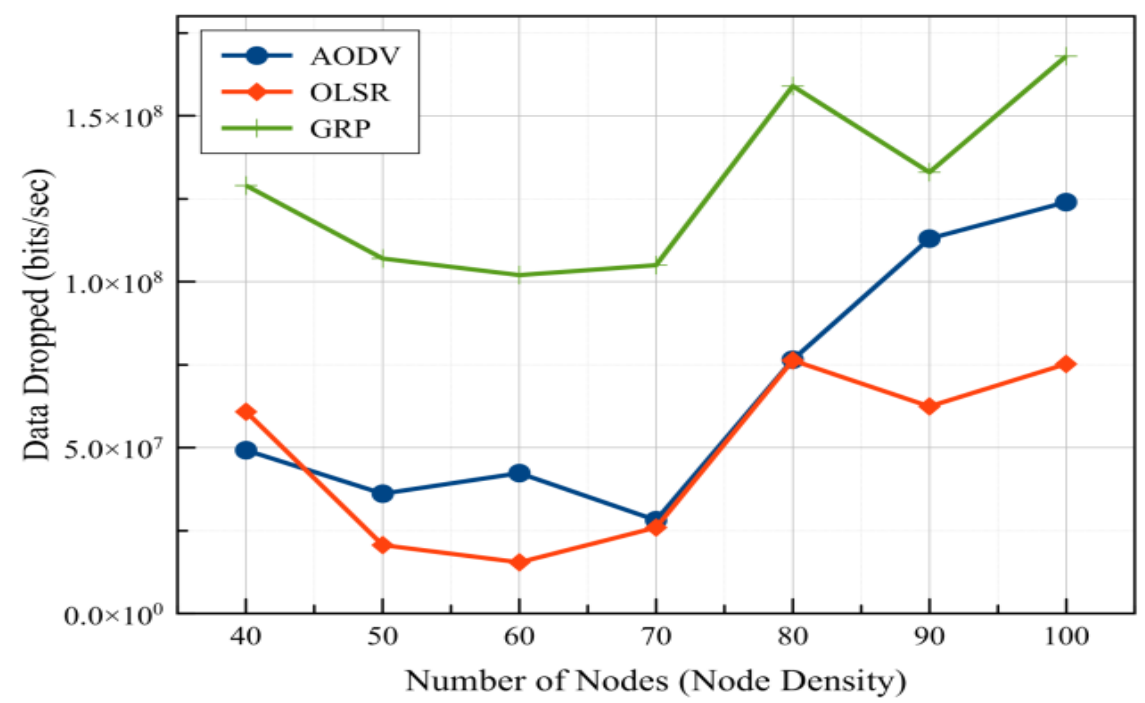

Figure 10. Data dropped (bits/sec) vs node density 


\section{CONCLUSION}

In this paper, the performance of the standard reactive routing protocol AODV over video streaming is evaluted. It was calculated in terms of various performance parameters such as average E2E-dealay, throughput, routing overhead, packet dropped, packet delivery ratio, retransmission attempts, and network load. We used in this study Video Conferencing to investigate the overall performance of the mentioned routing protocol for video streaming over MANETs. The scenario represents (small scale/low mobility density), in this scenario, the retransmission attempts, where in terms of throughput AODV is the better one. As Compared with GRP and GRP, AODV is very poor and worst in terms of jitter because AODV is generally a demand-based routing protocol. While AODV is similar to OLER data dropped in the range [70 to 80] mobile nodes, but if the number of mobile nodes exceeds 80 nodes data dropped start to increases. GRP is the worst case in terms of data dropped.

\section{REFERENCES}

[1] Bharathi, "A Review and Comparative Study on Various Routing Protocols for MANET," International Journal of Innovative Research in Science, Engineering and Technology, vol. 5, pp. 20790 - 20795, 2016.

[2] Ahmed, Diaa Eldein Mustafa and Khalifa, Othman Omran (2017) An overview of MANETs: applications, characteristics, challenges and recent issues. International Journal of Engineering and Advanced Technology, 6 (4). pp. 128-133. ISSN 2249-8958.

[3] S. Raja and K. Alagarsamy, Routing Protocols in MANET QoS Survey, International Journal of Innovative Research in Advanced Engineering (IJIRAE), vol. 2, pp. 169 -157, 2015.

[4] Singh,, Hm Dhiman, M. and Sehgal, P. K., A Survey on Video Streaming Schemes over MANETs, International Journal of Engineering Research and Applications, Vol. 2, Issue 3, May-Jun 2012, pp.1116-1122

[5] Diaa Eldin Mustafa Ahmed, Othman O. Khalifa, Aisha Hassan Abdalla Hashim:, Mudathir Yagoub Performance Evaluation of Ad hoc On-Demand Distance Vector Routing Protocol under Video Streaming, 2018 7th International Conference on Computer and Communication Engineering (ICCCE), 19-20 Sept. 2018, pp. 338-342.

[6] D. Muhit, Performance Evaluation Of Aodv, Dsr, Dsdv Mobile Ad-Hoc Protocols On Different Scenarios: An Analytical Review," International Journal of Advances in Computing and Information Technology, 2012

[7] B. Jagdale, P. Patil, P. Lahane, and D. Javale, Analysis and Comparison of Distance Vector, DSDV and AODV Protocol of MANET, International Journal of Distributed and Parallel Systems, vol. 3, p. 121, 2012.

[8] K. Gorantala, Routing protocols in mobile adhoc networks, A Master'thesis in computer science, pp-1-36, 2006.

[9] Charles Edward Perkins, Elizabeth M. Belding, Ad-hoc On-Demand Distance Vector Routing, Workshop on Mobile Computing Systems and Applications February 25-26, 1999, New Orleans, LA, USA.

[10] Sanam Narejo, Farzana Kulsoom, M. Moazzam Jawaid, Performance Evaluation of Interactive Video Streaming over WiMAX Network, International Journal of Electrical and Computer Engineering (IJECE) Vol. 7, No. 1, February 2017, pp. 344 352.

[11] Mehmet Umut Demircin, Robust Video Streaming Over Time-Varying Wireless Networks, PhD thesis, Georgia Institute of Technology, August 2008.

[12] Vinod B Durdi, P. T. Kulkarni, and K. L. Sudha," Robust Video Transmission over Wireless Networks Using Cross Layer Approach", Journal of Industrial and Intelligent Information Vol. 1, No. 2, June 2013:

[13] Kalvein Rantelobo, Wirawan, G. Hendrantoro, A. Affandi, and Hua-An Zhao, "A New Scheme for Evaluating Video Transmission over Broadband Wireless Network “, Future Wireless Networks and Information Systems, LNEE 143, pp. 335-341, Springerlink.com @ S Springer-Verlag Berlin Heidelberg 2012

[14] S.M. Koli, R.G. Purandare, S.P. Kshirsagar, and V.V. Gohokar, "A Survey on Video Transmission Using Wireless Technology“", CCSIT 2011, Part II, CCIS 132, pp. 137-147, Springer-Verlag Berlin Heidelberg 2011.

[15] Bernd Girod, Mark Kalman, Yi J. Liang and Rui Zhang ," Advances in channel-adaptive video streaming", Wireless Communications and Mobile Computing Special Issue: Multimedia Over Mobile IP ,Volume 2, Issue 6, pages 573-584, September 2002.

[16] Hazzaa, F. and Yousef, S., Performance Analysis for Traffics in Mobile Ad Hoc Network, International Conference on Global Security, Safety, and Sustainability, pp. 342-350, 2017.

[17] B. S. Kushwaha and P. K. Mishra, Different Traffic Patterns Over Ad Hoc Network Routing Protocols, International Journal of Computer Applications, vol. 138, pp. 1-5, 2016.

[18] R. Chandrakar, A. Kushwaha, and N. Choubey, Evaluation of routing protocols AODV, DSR and DSDV to enhance video transmission over Mobile Ad hoc Networks," in Signal Processing And Communication Engineering Systems (SPACES), 2015 International Conference on, 2015, pp. 67-71.

[19] P. N. Sadigale and S. Nagtilak, "Comparative Performance analysis of MANET Routing Protocols for Real Time Multimedia Applications," International Journal, vol. 3, 2015.

[20] H. J. Alqaysi and G. A. QasMarrogy, Performance Analysis Of Video Streaming Application Over Manets Routing Protocols,International Journal Of Research In Computer Applications And Robotics, vol. 3, pp. 22 -28, 2015.

[21] A. A. S. Wardaku, R. Paulus, A. Jaiswal, and A. Ashok, Performance Analysis of Multimedia Traffic in MANET with varying speed of mobile subscriber using CBR and VOIP," International Journal of Current Engineering and Technology, vol. 4, pp. 3999 - 4003, 2014.

[22] B.U. Islam, R.F. Olanrewaju, F. Anwar, A.R. Najeeb, M. Yacoob, "A Survey on MANETs: Architecture, Evolution, Applications, Security Issues and Solutions," Indonesian Journal of Electrical Engineering and Computer Science, 12(2), pp. 832-842, 2018. 


\section{BIOGRAPHIES OF AUTHORS}
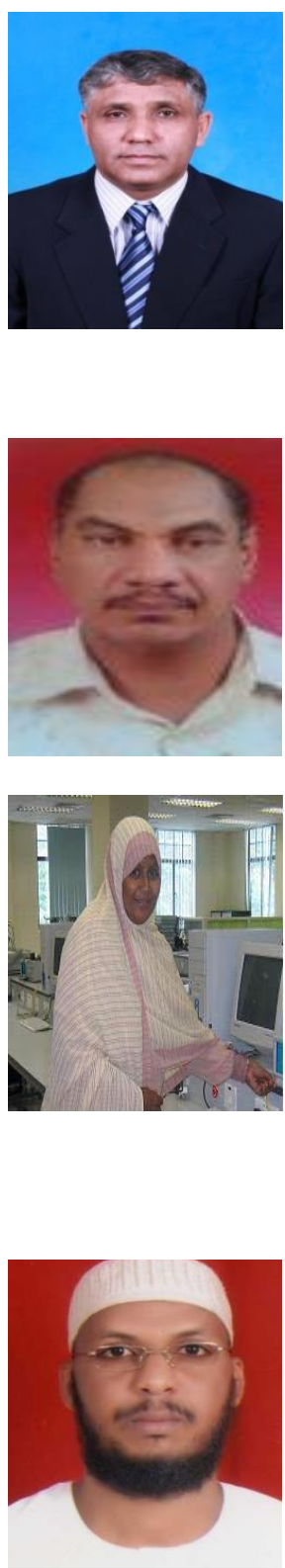

Othman Omran Khalifa received his Bachelor's degree in Electrical Engineering from the Garyounis University, Libya in 1986. Prof. Khalifa obtained his MSc and PhD in 1996, 2000 respectively from Newcastle University, UK. He joined International Islamic University Malaysia in August 2002. Prof. Khalifa served as a head of department of Electrical and computer Engineering, IIUM from July 2005 until December 2014. Prof. Khalifa is Charter Engineer and a senior member of IEEE, USA and a member IET, UK, a member of the International Association of Engineers (IAENG). Prof. khalifa was the chairman of the International Conference on Computer and Communication Engineering (ICCCE), 2006, 2010, 2012, 2014. Prof. Khalifa has extensively contributed through his writings in international journals, conferences and books. He published more than 410 publications including 10 books. $\mathrm{He}$ is a member of many international advisory boards for many international conferences.

Diaa Eldein Mustafa Ahmed received his in Engineering and Architecture from Khartoum university in 1995, he obtained his MSc(s) degree in 1996 in Mathematical Science from ALNeailain University, Sudan and another MSc degre in 2002 in Computer Science and Information from Al-Gazira university, Sudan. He is a head Department of Information Technology -University of Science and Technology -Sudan -Omdurman. Currently, he is a Ph.D researcher in wireless networks at Faculty of Computer Science and Information Technology, University of Science and Technology, Sudan.

Aisha Hassan Abdalla Hashim received her PhD in Computer Engineering (2007), M.Sc. in Computer Science (1996), and B.Sc. in Electronics Engineering (1990). She joined IIUM in 1997 and currently working as a Professor at the Department of Electrical and Computer Engineering. Professor Aisha is actively participating in curriculum development and program accreditation. She has been appointed as external examiner/visiting professor/adjunct professor at different universities. Professor Aisha is actively involved in research and postgraduate programs. She has published more than 250 journal/conference papers. She has supervised/cosupervised more than $60 \mathrm{PhD} /$ Master students. She has acquired several research grants from IIUM, Ministry of Higher Education (MOHE) and Ministry of Science, Technology and Innovation (MOSTI). She has actively contributed as a reviewer/technical committee member of many journals/conferences. She is senior member of IEEE and a member of IEE professional bodies.

Mudathir Fadoul received his BSc degree from the Omdurman Islamic University Faculty of Science and Technology in 2002. He finished the M.SC Degree (with Excellent) in Computer Science in 2010. Currently, he is a Ph.D researcher in wireless networks include Wireless Sensor Networks, Mobile Ad hoc Networks, Routing Protocols, Internet and Web of Things at Faculty of Computer Science and Information Technology, University of Science and Technology, Sudan. Mr Fadoul is a member of IEEE. 